\title{
Left ventricle geometry, echoreflectivity and CYP11B2 polymorphism C-344T in hypertensive males
}

\author{
Lozinska Marina, Zhebel Vadym, Lozinsky Sergiy*
}

Vinnytsia National Pirogov Medical University, Department of Internal Medicine of the Medical Faculty N02 56 Pirogov Str., Vinnytsia UA-21018, Ukraine

\section{Correspondence}

Lozinsky Sergiy, Vinnytsia National Pirogov Medical University, Department of Internal Medicine of the Medical Faculty N02 56 Pirogov Str., Vinnytsia UA-21018, Ukraine

Email: lozserg1@gmail.com

History

- Received: Feb 03, 2019

- Accepted: Mar 06, 2019

- Published: Mar 29, 2019

DOI : 10.15419/bmrat.v6i3.525

\section{Check for updates}

\section{Copyright}

(C) Biomedpress. This is an openaccess article distributed under the terms of the Creative Commons Attribution 4.0 International license.

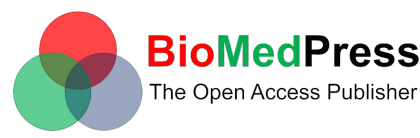

\begin{abstract}
Objectives: Hypertensive heart remodeling requires the assumption of different factors, including an increase of left ventricular mass (LVM) and myocardial fibrosis. It was shown that aldosterone stimulates cardiac collagen synthesis and fibroblast proliferation. CYP11B2 is one of the genes responsible for the effects of aldosterone. Therefore, hypertensive remodeling could be partially related to the polymorphism of this gene. The purpose of this study was to assess the association of CYP11B2 polymorphism with structural remodeling by changes in geometry and myocardial density to define their role and interaction in hypertensive heart disease. Methods: The study recruited 150 men aged 45-60 with and without essential hypertension (EH), who possessed no irreversible target organ damages. Fifty of them had normal BP, 58 had EH without left ventricular hypertrophy (LVH) and 42 had EH and LVH. Each participant underwent office blood pressure measurement, echocardiography with echo-reflectivity analysis, and determination of the C-344T polymorphism of the aldosterone synthase gene CYP11B2. Results: Patients with EH and LVH differed not only by LV mass but also by larger body mass, relative wall thickness, and wider echo-reflectivity spectrum. The associations of larger end diastolic diameter with C allele, and the larger thickness of the posterior wall and interventricular septum with T allele, were revealed only in patients with $\mathrm{EH}$ and $\mathrm{LVH}$. Conclusions: Hypertensive patients with LVH are likely to be a distinct cluster with their own genetic predisposition to hypertensive heart disease.

Key words: essential hypertension, hypertensive heart remodeling, myocardial fibrosis, echoreflectivity, CYP11B2 polymorphism
\end{abstract}

\section{INTRODUCTION}

Aldosterone plasma activity plays an important role in the general homeostasis. The retention of water and electrolytes is a common mechanism of blood pressure up-regulation that impacts not only BP level, but also myocardial remodeling. LVH is the most common sequelae of hypertension and is a result of cardiac remodeling and hypertrophy. It is a strong risk factor for cardiovascular events and all-cause mortality, especially arrhythmias and sudden cardiac death ${ }^{1}$. Hypertensive heart remodeling involves different processes. An increase of left ventricular mass (LVM) is the most popular event beside myocardial fibrosis. It has been shown that aldosterone stimulates cardiac collagen synthesis and fibroblast proliferation via activation of local mineralocorticoid receptors in the heart $^{2}$. CYP11B2 is one of the genes responsible for the effects of aldosterone, thus, hypertensive remodeling could be partially related to the polymorphism of this gene. Up to date, we have no reliable methods of estimation of fibrosis, and the question of how it contributes to the phenotype of hypertensive heart disease remains unexplored. We tried to assess the association of CYP11B2 polymorphism with structural remodeling by changes in geometry and myocardial density, aiming to define their role and interaction in hypertensive heart disease.

\section{METHODS}

The protocol of the study was approved by the local ethics commission of Vinnytsia Regional Dispensary of Radiation Defense of Population. The informed consent was mandatory for all participants. The study involved men aged 45-60 years old, with or without essential hypertension (EH), who had no irreversible target organ damages. Diagnosis of hypertension was established according to the ESC recommendations (2013). The group of normotensive persons, including men of the same age with normal blood pressure and without any pathological changes detected by echocardiography (ECG). The age criteria covered most patients with hypertension. The criteria for exclusion from the study were as follows:

- Congenital or acquired heart defects

- Systemic connective tissue diseases

- Endocrine diseases 
- Chronic kidney disease

- Secondary essential hypertension

- Myocardial disease and heart failure not associated with essential hypertension

- Pulmonary essential hypertension

- Hemodynamically significant arrhythmias (atrial fibrillation or flutter, AV blocks of $2^{\text {nd }}$ and $3^{\text {rd }}$ degree, high-grade premature beats)

- Unsatisfactory ultrasound visualization of the heart

- DM of 1 type or uncontrolled DM of type 2

- Unstable or variant angina on the day of inclusion.

The patients involved in the study did not receive regular antihypertensive therapy. Each participant underwent the following activities: office blood pressure measurement (according to the recommendations by the ESC), echocardiography with echo-reflectivity analysis, and determination of the polymorphism of the aldosterone synthase gene CYP11B2.

Basic measurements of left ventricle such as end diastolic and end systolic dimensions (EDD and ESD), left ventricular mass indexed by the body area (LVMI), ejection fraction (EF), relative wall thickness (RWT) were obtained by echocardiography. Echocardiography had been performing using Sigma 5000 equipment (Kontron Medical, France). We located 2 representative areas $2010 \mathrm{~mm}$ in size, one in the interventricular septum, and another in an LV posterior wall, on the images in the parasternal long axis view and saved them for the future processing. During the procession, the broadband ( $\mathrm{BB})$ of the black and white spectrum of chosen regions of interest was calculated by Image J software in an offline mode. Figure 1 demonstrates an example of such processing of the images. According to available resources, this parameter is the most reliable echo-reflectivity marker of myocardial fibrosis. In an experimental study, its correlation with collagen volume fraction measured by biopsy was as high as $0.72(\mathrm{p}=0.03)^{3}$.

The polymorphism of the CYP11B2 gene was determined from venous blood samples of all participants by PCR method. Blood genomic DNA was extracted using a set of reagents purchased from LLC NPF Synthol, Russia. Polymorphic regions of CYP11B2 gene were amplified by a polymerase chain reaction. The final volume of the reaction mixture was $25 \mu \mathrm{L}$ and consisted of:
- Specific oligonucleotide primers: 5' - CAG GAG GAGACC CCA TGT GAC -3 '; 5'- CCT CCA CCC TGT TCA GCC C - 3 ';

- $2.5 \mu \mathrm{L}$ of $10 \mathrm{X}$ buffer for amplification;

- $2 \mathrm{mM}$ of magnesium chloride

- $0.2 \mathrm{mM}$ of mixture of deoxynucleotide triphosphates (dNTP)

- 2.5 units of Taq DNA polymerase

- 20-50 ng of genomic DNA

- $25 \mu \mathrm{L}$ of mineral oil was poured into the test tubes

The amplification was performed on the amplifier "Tertsik" (LLC "DNA-Technology", Russia), using the amplification program, which started with a denaturation at $94^{\circ} \mathrm{C}$ for 5 minutes, following by 35 cycles of amplification. For the identification of the alleles, we carried out a restrictive analysis of the amplicons, using endonuclease restriction HaeIII (SibEnzyme, Russia) at $37^{0} \mathrm{C}$.

The cleavage products of the polymorphic sites of CYP11B2 gene were detected by electrophoresis in $5 \%$ agarose gel (Agarose SFR, AMRESCO, USA), in a single TBE buffer (50 mM Tris-H3BO3 and $2 \mathrm{mM}$ EDTA, pH 8.0) for 1 hour at $3-4 \mathrm{~V}$ per $1 \mathrm{~cm}$ of gel. PbR322/AluI was used as DNA ladders. Gels were stained with ethidium bromide, followed by visualization of results under UV-light.

\section{RESULTS}

A total of 50 men with normal blood pressure and 100 patients with $\mathrm{EH}$ were examined. Among those, 58 participants had hypertension without any damages of the target organs and all had normal LVM. Other 42 patients had hypertension with the ECG signs of LV hypertrophy, established on the values of LVMI > = $110 \mathrm{~g} / \mathrm{m}^{2}$, or had at least one of the LV walls exceeded $12 \mathrm{~mm}$ in thickness. The results of anthropometry and echocardiography are presented below (Table 1).

All groups did not differ in their ages and height. However, group 2 and 3 showed higher body mass compared to group 1 (Figure 2). This observation was the same for the SBP and DBP parameters (Figure 3). LVM differed dramatically: the indexed means LVM were almost the same in the $1^{\text {st }}$ and $2^{\text {nd }}$ groups, while in the $3^{\text {rd }}$ group, they were much higher. Changes of RWT were similar in all groups (Figure 4).

Differences in LV dimensions and ejection fraction between groups were not significant. The results of 



Figure 1: Analysis of echoreflectivity. The left panel performs an LV image with the region of interest (ROI) marked by a yellow rectangle. The right panel performs the gray scale spectrum of the ROI.

Table 1: Anthropometry and echocardiography measurements in groups 1, 2 and 3

\begin{tabular}{llll} 
& $\begin{array}{l}\text { NT (Group 1), M (SD) } \\
\mathrm{n}=50\end{array}$ & $\begin{array}{l}\mathrm{EH}(\text { Group 2), M (SD) } \\
\mathrm{n}=58\end{array}$ & $\begin{array}{l}\text { EH+LVH (Group 3), M (SD) } \\
\mathrm{n}=42\end{array}$ \\
\hline $\begin{array}{l}\text { Mean age, y. } \\
\text { Height, sm }\end{array}$ & $51.8(5,5)$ & $52.3(5,3)$ \\
Weight, kg & $174.3(12,3)$ & $176.4(8,5)$ & $177.4(4,8)$ \\
SBP, mm Hg & $81.4(13,2)$ & $95.3(21,2)$ & $101.9(15,5)$ \\
DBP, mm Hg & $124.4(15,8)$ & $151.6(19,4)$ & $160.2(21,8)$ \\
EDD, mm & $75.1(9,9)$ & $92.8(11,6)$ & $94.7(13,3)$ \\
ESD, mm & $48.6(5,2)$ & $48.9(5,2)$ & $52.1(5,6)$ \\
EF, \% & $32.7(4,1)$ & $33.3(4,5)$ & $34.3(5,6)$ \\
LVM, g/m2 & $61.2(7,7)$ & $59.9(7,7)$ & $59.7(10,6)$ \\
RWT & $82.3(16,9)$ & $82.9(18,7)$ & $131.4(25,5)$ \\
\hline
\end{tabular}

NT - normal BP; EH -essential hypertension; EH+LVH - essential hypertension and left ventricularhypertrophy; SBP - systolic blood pressure; DBP - diastolic blood pressure; EDD- end-diastolic dimension; ESD - endsystolic dimension; EF - ejection fraction; LVM - left ventricular mass; RWT -relative wall thickening

CYP11B2 genotyping showed that there were 31 owners of CC, 77 of TC, and 42 of TT genotypes among 150 examined males. We checked our samples for agreement with Hardy-Weinberg equilibrium using $\chi^{2}$ test and found that the differences between actual and theoretically calculated distributions were not significant $\left(\chi^{2}=2.07 ; \mathrm{p}=0.35\right)$. The distribution of CYP11B2 polymorphism in the groups of our study is shown in the Table 2. It was shown that all groups did not differ significantly, although there were a slight increase of the TC and a decrease of the CC genotype prevalence in hypertensive patients with LVH.

There were no significant differences associated with a CYP11B2 polymorphism in normotensive men, although in both groups of hypertensive males (with and without LVH), EDD was significantly higher in allele C carriers (CC and TC genotypes). At the same time, the posterior wall and interventricular septum seemed to be thicker in carriers of $\mathrm{T}$ alleles. This trend was statistically significant in hypertensive patients with LVH (Group 3). This explains why there were no differences in LVMI within both groups of hypertensive males, but there were significant increase in RWT with the increase of $\mathrm{T}$ allele numbers (Table 3 ).

High echo-reflectivity is a possible marker of disorders in an intrinsic architecture of myocardium. In theory, an increase in high-density elements of myocardium, such as collagen fibers, leads to the increase of ultrasound reflections that could be detected by the device capable to detect the difference in power of waves moving forward and backward, thus, it was socalled backscatter. For more accurate estimation of 


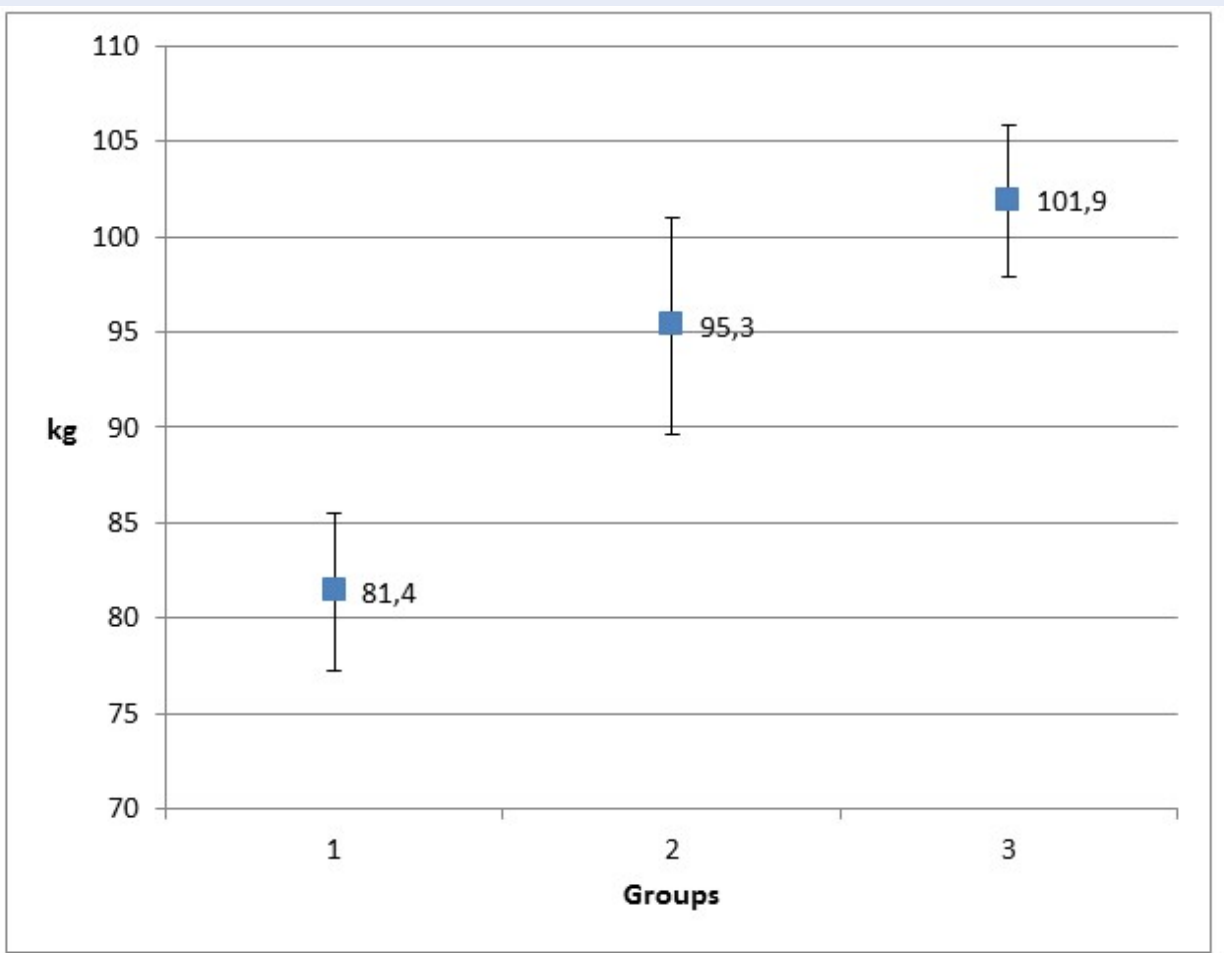

Figure 2: Means of body mass and $95 \% \mathrm{Cl}$ in groups of patients.
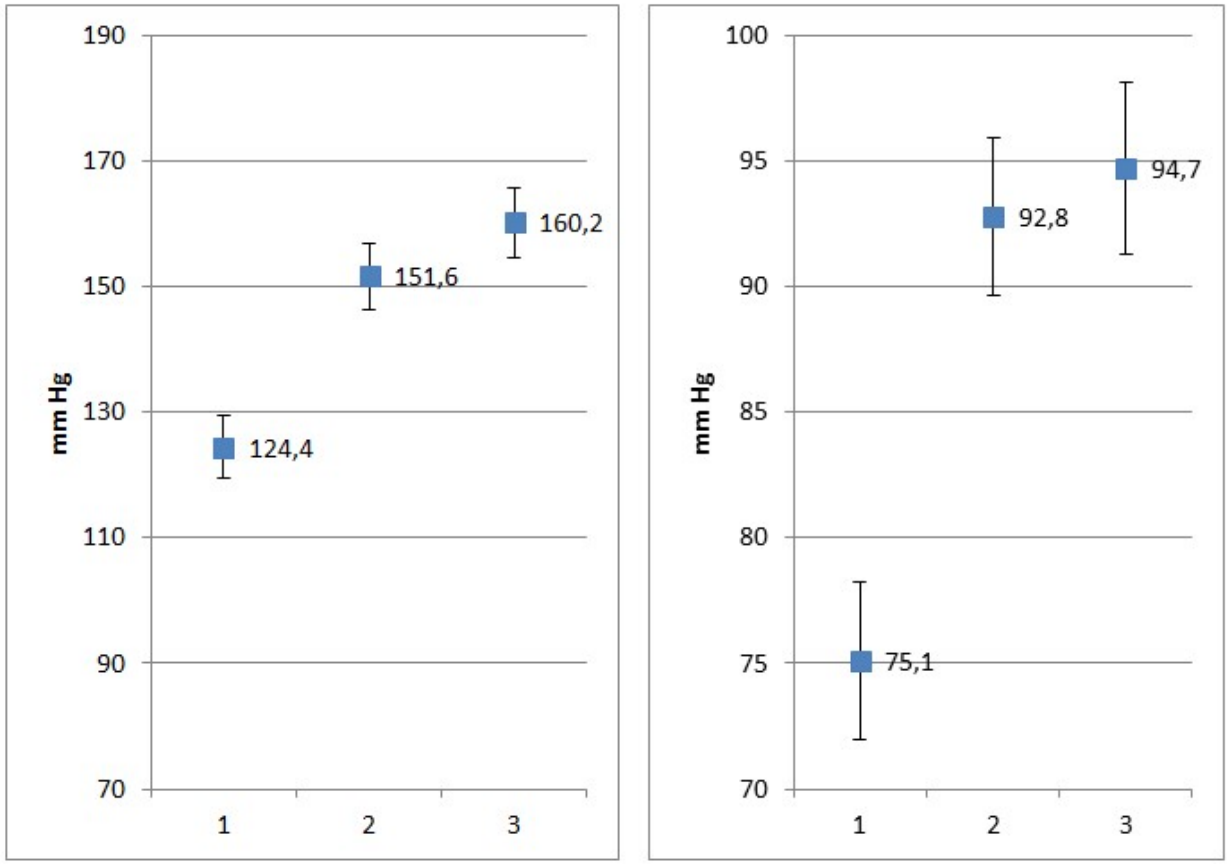

Figure 3: The average values and $95 \% \mathrm{Cl}$ of SBP (left panel) and DBP (right panel) in groups of patients. 

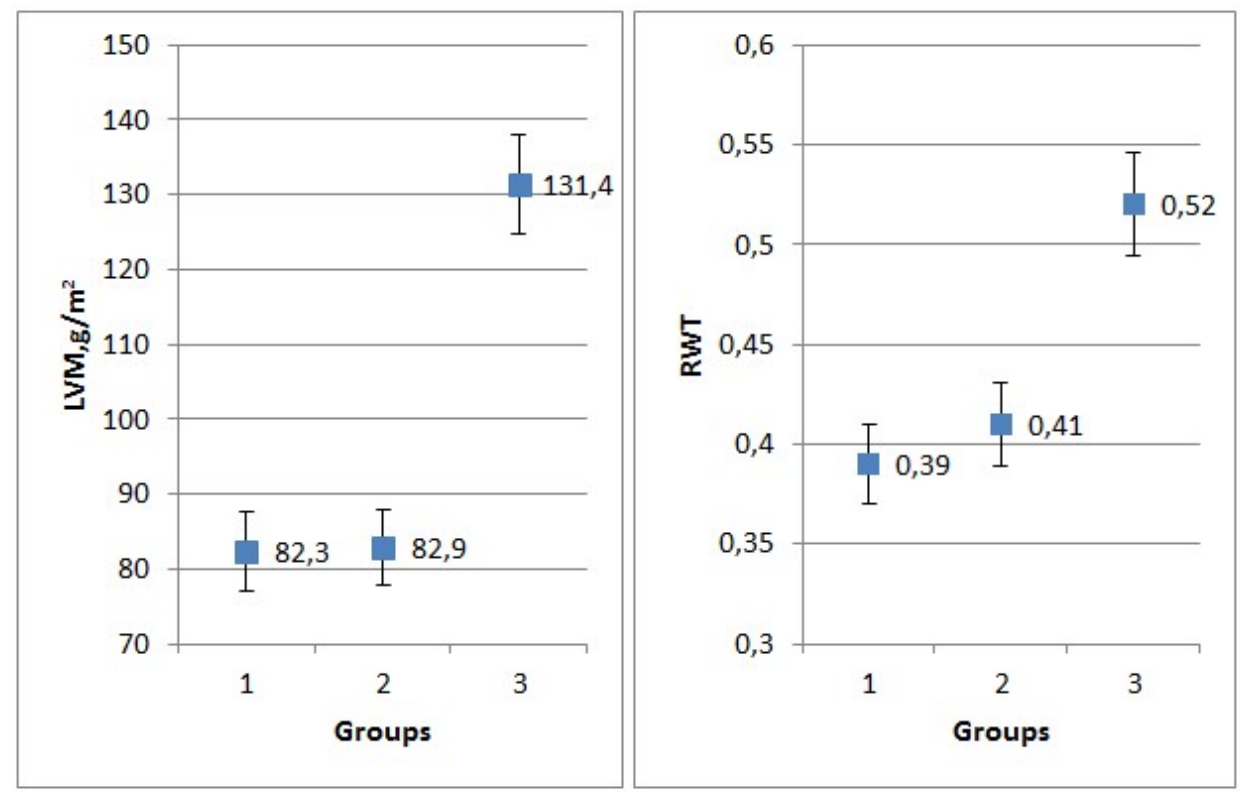

Figure 4: Indexed LVM (left panel) and RWT (right panel) with $95 \% \mathrm{Cl}$.

Table 2: The distribution of CYP11B2 polymorphism in normotensive, hypertensive, and hypertensive with LV hypertrophy patients

\begin{tabular}{llllll}
\hline Groups & CC & TC & TT & $\chi^{2}$ & p \\
\hline NT $(n=50)$ & $12(0.24)$ & $24(0.48)$ & $14(0.28)$ & & \\
EH (n=58) & $12(0.20)$ & $29(0.50)$ & $17(0.30)$ & 0.17 & 0.91 \\
EH+LVH (n=42) & $7(0.17)$ & $24(0.57)$ & $11(0.26)$ & 0.98 & 0.61 \\
\hline
\end{tabular}

$\chi^{2}$ - the significance of differences of $\mathrm{EH}$ and $\mathrm{EH}+\mathrm{LVH}$ groups comparing with NT group

backscatter, two or more myocardium regions were used for averaging of the means. Also, myocardium backscatter is usually compared with backscatter of the toughest heart structures of the same patient such as pericardium (calibration of backscatter). This method is known as an integrated calibrated backscatter.

Another way of reflected signal estimation is a processing of grayscale images of myocardium by the external software, such as ImageJ, in the offline mode. Since the greyscale has 256 standard tint gradations represented by a certain number of pixels, the general image information can be represented as a column (frequency) graph, which displays the number of pixels for each tint. The most useful parameter of echo-reflectivity analysis is broadband (BB), which indicates the width of the grayscale spectrum. As with the integrated calibrated backscatter, to obtain more accurate meanings, a minimum of 2 regions of interest
(ROI) were chosen: one in the middle of the interventricular septum, and the other - in the posterior wall of left ventricle. The means of $\mathrm{BB}$ could be obtained as an average of these two values. Echo-reflectivity was estimated in all patients in the above-mentioned manner.

It was found that the mean range of spectrum in hypertensive males with LVH (Group3) was significantly wider $(\mathrm{p}<0.001)$ than in normotensives and hypertensives without LVH (Figure 5).

\section{DISCUSSION}

According to current knowledge, hypertensive cardiac remodeling is characterized not only by the increase of the muscle fiber thickness and myocardial mass, but also by the changes in micro-circulation with the extension of relative coronary insufficiency and myocardial fibrosis. 
Table 3: Results of echocardiographic measurements in groups 1, 2, and 3 of patients depending on CYP11B2 polymorphism

\begin{tabular}{|c|c|c|c|c|c|c|c|c|c|c|c|c|}
\hline & \multicolumn{4}{|l|}{ Group 1} & \multicolumn{4}{|c|}{ Group 2} & \multicolumn{4}{|c|}{ Group 3} \\
\hline & $\begin{array}{l}\text { CC } \\
(n=12)\end{array}$ & $\begin{array}{l}\text { TC } \\
(\mathbf{n}=\mathbf{2 4})\end{array}$ & $\begin{array}{l}\text { TT } \\
(n=14)\end{array}$ & $p$ & $\begin{array}{l}\text { CC } \\
(n=12)\end{array}$ & $\begin{array}{l}\text { TC } \\
(n=29)\end{array}$ & $\begin{array}{l}\text { TT } \\
(n=17)\end{array}$ & $p$ & $\begin{array}{l}\text { CC } \\
(n=7)\end{array}$ & $\begin{array}{l}\text { TC } \\
(n=24)\end{array}$ & $\begin{array}{l}\text { TT } \\
(n=11)\end{array}$ & $p$ \\
\hline EDD & $50.7(4.4)$ & $\begin{array}{l}48.0 \\
(4.1)\end{array}$ & $\begin{array}{l}47.6 \\
(5.4)\end{array}$ & 0.19 & $\begin{array}{l}52.4 \\
(5.6)\end{array}$ & $\begin{array}{l}47.8 \\
(4.4)\end{array}$ & $\begin{array}{l}48.6 \\
(4.8)\end{array}$ & 0.04 & $\begin{array}{l}56.2 \\
(6.6)\end{array}$ & $\begin{array}{l}51.4 \\
(5.0)\end{array}$ & $\begin{array}{l}50.5 \\
(2.6)\end{array}$ & 0.01 \\
\hline ESD & $34.3(4.7)$ & $\begin{array}{l}32.4 \\
(3.7)\end{array}$ & $\begin{array}{l}31.9 \\
(3.9)\end{array}$ & 0.27 & $\begin{array}{l}35.5 \\
(4.7)\end{array}$ & $\begin{array}{l}32.3 \\
(4.2)\end{array}$ & $\begin{array}{l}33.5 \\
(5.5)\end{array}$ & 0.19 & $\begin{array}{l}36.8 \\
(5.3)\end{array}$ & $\begin{array}{l}34.5 \\
(4.9)\end{array}$ & $\begin{array}{l}31.9 \\
(3.9)\end{array}$ & 0.04 \\
\hline PWL & $9.1(1.7)$ & $\begin{array}{l}9.6 \\
(1.2)\end{array}$ & $\begin{array}{l}9.3 \\
(1.1)\end{array}$ & 0.50 & $\begin{array}{l}9.4 \\
(0.7)\end{array}$ & $\begin{array}{l}10.0 \\
(1.7)\end{array}$ & $\begin{array}{l}10.0 \\
(1.4)\end{array}$ & 0.48 & $\begin{array}{l}11.5 \\
(0.9)\end{array}$ & $\begin{array}{l}13.2 \\
(1.9)\end{array}$ & $\begin{array}{l}12.8 \\
(1.4)\end{array}$ & 0.04 \\
\hline IVSL & $9.2(1.1)$ & $\begin{array}{l}9.2 \\
(1.4)\end{array}$ & $\begin{array}{l}9.2 \\
(1.8)\end{array}$ & 0.90 & $\begin{array}{l}8.9 \\
(1.3)\end{array}$ & $\begin{array}{l}10.0 \\
(1.6)\end{array}$ & $\begin{array}{l}9.9 \\
(1.6)\end{array}$ & 0.12 & $\begin{array}{l}12.0 \\
(1.7)\end{array}$ & $\begin{array}{l}13.9 \\
(2.4)\end{array}$ & $\begin{array}{l}14.6 \\
(2.2)\end{array}$ & 0.02 \\
\hline LVM & $86.1(13.3)$ & $\begin{array}{l}83.1 \\
(16.4)\end{array}$ & $\begin{array}{l}77.4 \\
(18.4)\end{array}$ & 0.37 & $\begin{array}{l}86.3 \\
(12.1)\end{array}$ & $\begin{array}{l}81.7 \\
(14.7)\end{array}$ & $\begin{array}{l}82.6 \\
(16.6)\end{array}$ & 0.71 & $\begin{array}{l}121.7 \\
(12.1)\end{array}$ & $\begin{array}{l}133.3 \\
(25.7)\end{array}$ & $\begin{array}{l}134.5 \\
(21.3)\end{array}$ & 0.36 \\
\hline RWT & $0.36(0.07)$ & $\begin{array}{l}0.40 \\
(0.05)\end{array}$ & $\begin{array}{l}0.39 \\
(0.05)\end{array}$ & 0.29 & $\begin{array}{l}0.35 \\
(0.04)\end{array}$ & $\begin{array}{l}0.43 \\
(0.48)\end{array}$ & $\begin{array}{l}0.42 \\
(0.08)\end{array}$ & 0.06 & $\begin{array}{l}0.43 \\
(0.08)\end{array}$ & $\begin{array}{l}0.53 \\
(0.12)\end{array}$ & $\begin{array}{l}0.54 \\
(0.06)\end{array}$ & 0.02 \\
\hline
\end{tabular}

Note: Group 1 - patients with normal pressure; Group 2 - patients with EH without LV changes; Group 3 -patients with EH and LVH; $p$ significance of differences within genotypes byKruskal-Wallis ANOVA

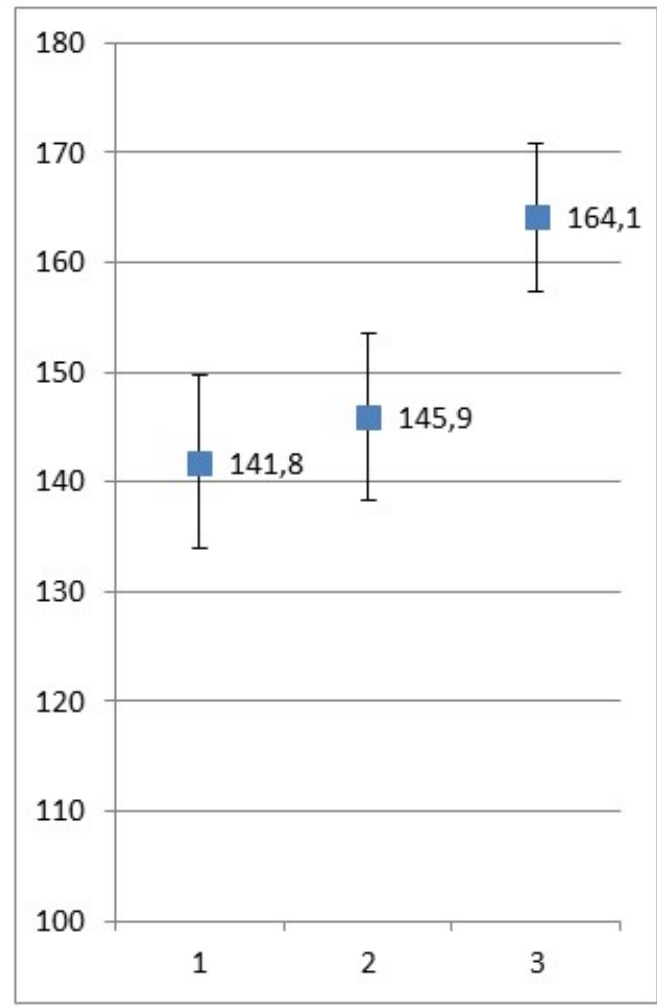

Figure 5: Means and 95\% Cl for BB in groups 1, 2 and 3. 
There is growing evidence that these factors may be genetically determined, thus, it is likely that the aldosterone synthase gene is one of the possible candidate genes. The data on CYP11B2 polymorphism prevalence in our study was similar to the studies completed in Ukraine and other countries, where the Caucasian populations such as Germany, Finland, Czech Republic, USA, and Uzbekistan were tested ${ }^{3-7}$. But they were different from orient countries (Japan, China, and Tibet) ${ }^{8-11}$ by the prevalence of CC genotype. The associations of larger EDD with the presence of $\mathrm{C}$ allele and larger PWD with TT presence were described earlier in a meta-analysis of WangL. et al. ${ }^{11}$. Therefore, our data are in agreement with modern views in this field. The only exception is the increase IVS thickness with $\mathrm{T}$ presence, which is in controversy with the abovementioned papers.

Our findings suggest that males with hypertension and LVH differ from patients without LVH, not only by LVMI, but also by the density of myocardium, although they have the same levels of OBP and anthropometric data. Also, the association of CYP11B2 polymorphism with LV structure remodeling was found in this group of patients but not normotensives and hypertensives without LVH. This remodeling includes significantly larger LVMI and accumulation of fibrotic tissue.

The present study has the limitations of age, gender and number of patients. It is unclear if there are any similar associations of LV structural remodeling with CYP11B2 polymorphism in other patient groups.

\section{CONCLUSIONS}

The received data allowed the assumption that hypertensive patients with LVH are likely a distinct cluster of patients with their own genetic predisposition to the formation of hypertensive heart disease traits.

\section{ABBREVIATIONS}

DBP: Diastolic blood pressure

DM: Diabetes mellitus

ECG: Echocardiography

EDD: End diastolic dimension

EF: Ejection fraction

EH: Essential hypertension

ESC: European society of cardiology

ESD: End systolic dimension

LVH: Left ventricular hypertrophy

LVM: Left ventricular mass

LVMI: Indexed left ventricular mass

OBP: Office blood pressure

PCR: Polymerase chain reaction

ROI: Region of interest

RWT: Relative wall thickness

SBP: Systolic blood pressure

\section{COMPETING INTERESTS}

The authors declare no conflict of interest.

\section{AUTHORS' CONTRIBUTIONS}

Lozinska M.: Data collection, statistical processing, literature review, discussion and conclusions final presentation. Zhebel V.: General conception and design, final approvement. Lozinsky S.: Study coordination, preliminary data analysis, took part in discussion and conclusions generation. All authors approved the final manuscript as submitted and agree to be acountable for all aspects of the work.

\section{REFERENCES}

1. Shenasa M, Shenasa H. Hypertension, left ventricular hypertrophy, and sudden cardiac deat. Int J Cardiol. 2017;237:60-3. 28285801. Available from: 10.1016/j.ijcard.2017.03.002.

2. Weber KT, Brilla CG. Pathological hypertrophy and cardiac interstitium. Circulation. 1991;83(6):1849-65. 1828192. Available from: 10.1161/01.CIR.83.6.1849.

3. Ciulla M, Paliotti R, Hess DB, Tjahja E, Campbell SE, Magrini $F$, et al. Echocardiographic patterns of myocardial fibrosis in hypertensive patients: endomyocardial biopsy versus ultrasonic tissue characterizatio. J Am Soc Echocardiogr. 1997;10(6):657-64. 9282355. Available from: 10.1016/S08947317(97)70028-2.

4. Alimuhamedova GA, Halimova ZY, Ismailov SI. Geneticheskie aspekty adrenal'nyh incidentalom. Novosti mediciny i farmacii. 2010;29(5):23-28.

5. Byrd JB, Auchus RJ, White PC. Aldosterone Synthase Promoter Polymorphism and Cardiovascular Phenotypes in a Large, Multiethnic Population-Based Study. J Investig Med. 2015;63(7):862-6. 26200036. Available from: 10.1097/JIM. 0000000000000220 .

6. Hlubocká Z, Já\}chymová M, Heller S, Umnerová V, Danzig V, Lánská V. Association of the -344T/C aldosterone synthase gene variant with essential hypertensio. Physiol Res. 2009;58(6):785-92. 19093739.

7. Kupari M, Hautanen A, Lankinen L, Koskinen P, Virolainen J, Nikkila $\mathrm{H}$, et al. Associations between human aldosterone synthase (CYP11B2) gene polymorphisms and left ventricular size, mass, and function. Circulation. 1998;97(6):569-75. 9494027. Available from: 10.1161/01.CIR.97.6.569.

8. Rajput C, Makhijani K, Norboo T, Afrin F, Sharma M, Pasha ST, et al. CYP11B2 gene polymorphisms and hypertension in highlanders accustomed to high salt intake. J Hypertens. 2005;23(1):79-86. 15643128. Available from: 10.1097/ 00004872-200501000-00016.

9. Song Y, Miyaki K, Araki J, Zhang L, Takahashi Y, Nakayama T, et al. Influence of CYP11B2 gene polymorphism on the prevalence of hypertension and the blood pressure in Japanese men: interaction with dietary salt intake. J Nutrigenet Nutrigenomics. 2008;1(5):252-8. 19776632. Available from: $10.1159 / 000150006$.

10. Tsukada K, Ishimitsu T, Teranishi M, Saitoh M, Yoshii M, Inada $\mathrm{H}$, et al. Positive association of CYP11B2 gene polymorphism with genetic predisposition to essential hypertension. J Hum Hypertens. 2002;16(11):789-93. 12444540. Available from: 10.1038/sj.jhh.1001484.

11. Wang L, Zhou J, Zhang B, Wang H, Li M, Niu Q, et al. Association of echocardiographic left ventricular structure and $-344 \mathrm{C} / \mathrm{T}$ aldosterone synthase gene variant: A meta-analysi. J Renin Angiotensin Aldosterone Syst. 2015;16(4):858-71. 25208931. Available from: 10.1177/1470320314535459. 